\title{
A Cross-Sectional Study of the Prevalence of Metabolic Syndrome and Associated Factors in Colombian Collegiate Students: The FUPRECOL-Adults Study
}

Javier Martínez-Torres ${ }^{1}$, Jorge Enrique Correa-Bautista ${ }^{2}$, Katherine González-Ruíz ${ }^{3}$, Andrés Vivas ${ }^{3}$, Héctor Reynaldo Triana-Reina ${ }^{4}$, Daniel Humberto Prieto-Benavidez ${ }^{2}$, Hugo Alejandro Carrillo ${ }^{4}$, Jeison Alexander Ramos-Sepúlveda ${ }^{5}$, Emilio Villa-González ${ }^{6,7}$, Antonio García-Hermoso ${ }^{8}$ and Robinson Ramírez-Vélez ${ }^{2, *}$

1 Grupo GICAEDS, Facultad de Cultura Física, Deporte y Recreación, Universidad Santo Tomás, Bogotá DC 110311, Colombia; javiermartinezt@usantotomas.edu.co

2 Centro de Estudios para la Medición de la Actividad Física «CEMA», Escuela de Medicina y Ciencias de la Salud, Universidad del Rosario, Bogotá DC 111221, Colombia; jorge.correa@urosario.edu.co (J.E.C.-B.), danielprietob@gmail.com (D.H.P.-B.)

3 Grupo de Ejercicio Físico y Deportes, Vicerrectoría de Investigaciones, Universidad Manuela Beltrán, Bogotá DC 110231, Colombia; katherine.gonzalez@docentes.umb.edu.co (K.G.-R.); jose.vivas@docentes.umb.edu.co (A.V.)

4 Grupo GRINDER, Programa de Educación Física y Deportes, Universidad del Valle, Santiago de Cali DC 760010, Colombia; hectortriana@usantotomas.edu.co (H.R.T.-R.); hugo.carrillo@correounivalle.edu.co (H.A.C.)

5 Facultad de Educación a Distancia y Virtual, Institución Universitaria Antonio José Camacho, Santiago de Cali DC 760010, Colombia; jeisonandres@yahoo.es

6 Department of Education Sciences, University of Almería, Almería DC 04120, Spain; evilla@unach.edu.ec

7 PROFITH “PROmoting FITness and Health through Physical Activity" Research Group, Department of Physical Education and Sport, School of Sport Sciences, University of Granada, Granada DC 18010, Spain

8 Laboratorio de Ciencias de la Actividad Física, el Deporte y la Salud, Facultad de Ciencias Médicas, Universidad de Santiago de Chile, USACH, Santiago DC 9160030, Chile; antonio.garcia.h@usach.cl

* Correspondence: robin640@hotmail.com or robinson.ramirez@urosario.edu.co; Tel.: +57-1-297-0200 (ext. 3428)

Academic Editor: Peter Clifton

Received: 17 December 2016; Accepted: 21 February 2017; Published: 27 February 2017

\begin{abstract}
Metabolic syndrome (MetS) is one of the major public health problems worldwide. The objective of the present study is to investigate the prevalence and the associated variables of MetS in Colombian collegiate students. This cross-sectional study included a total of 890 ( $52 \%$ women) healthy collegiate students $(21.3 \pm 3.2$ years old $)$. The prevalence of MetS was determined by the definition provided by the International Diabetes Federation (IDF). We further examined associations between the prevalence of MetS and related factors, such as age, gender, anthropometric and body composition, weight status, and nutrition profile. The overall prevalence of MetS was $6.0 \%$ $(95 \% \mathrm{CI}=4.5 \%$ to $7.6 \%)$, and it was higher in men than women. The most prevalent components were low high-density lipoprotein cholesterol, high triglyceride levels, waist circumference, and blood pressure levels. The predisposing factors for having a MetS included: being male, over 23 years old, overweight or obese, and having an unhealthy waist-to-height ratio. In conclusion, the occurrence of MetS in young adults is substantial. These findings may be relevant to health promotion efforts for collegiate students in order to develop prospective studies and screening for young adults, which will aid in targeted intervention development to decrease cardiometabolic risk factors.
\end{abstract}


Keywords: prevalence; cardiometabolic risk factors; obesity; cardiovascular disease

\section{Introduction}

Metabolic syndrome (MetS) is a major public health problem worldwide [1]. A diagnosis of MetS is based on the existence of pre-diabetes combined with dyslipidemia (elevated levels of total or low-density lipoprotein cholesterol, or low high-density lipoprotein cholesterol levels), elevated blood pressure and central adiposity [2,3]. The screening and early diagnosis of MetS are, however, not easy in young subjects, because the diagnostic criteria for the estimation of MetS has not been fully established [3]. Identifying individuals with MetS is important due to its association with an increased risk of coronary heart disease and Type 2 diabetes mellitus [4-8]. For this reason cardiovascular risk factor measurements are important, even at early age, to detect a risk profile in time for intervention.

On the other hand, several risk factors for MetS have been suggested, such as weight status [9], measures of central adiposity and inflammatory markers [10], dietary factors, such as the intake of total fat or saturated fat [11], physical inactivity [12], and poor physical fitness [13]. We previously demonstrated in children and adolescents aged 9-17 years that those with the highest values of body mass index and subjects aged 9-12 years old were more likely to have a prevalence of MetS [3]. Additionally, other studies that included diverse Hispanic/Latino populations suggested a marked heterogeneity in risk factor prevalence within this population $[7,8]$.

Currently, there is no gold standard diagnostic criteria for MetS in adults, and a description of the prevalence of MetS according to the few proposed definitions is necessary for different populations around the world [4,5]. For example, the National Health and Nutrition Examination Survey reported that when using the National Cholesterol Education Program definition of the MetS $[4,6]$, the age-adjusted prevalence of the MetS was $44.5 \%$ among Hispanic men, and $44.1 \%$ among Hispanic women $[7,14-16]$. Furthermore, previous studies in the Colombian population have shown an inconsistent association between the component cut-offs specified in diagnostic criteria for MetS and its utility $[17,18]$.

The lifestyle of the college population has changed considerably over the past 20 years due to a rapid improvement in socioeconomic status $[19,20]$. These changes, in addition to the adoption of a western lifestyle and diet, have led to a rise in the prevalence of overweight and obesity in Colombians, particularly among university students [17]. Other studies has reported MetS in younger populations but use a much wider age range [3] or include non-college students [7-9]. Additionally, it was challenging to clearly define the "young adult" age group. In previously reported cross-sectional studies, the MetS prevalence in adolescents included ages 12-18 years [3] or 10-19 years old [16]. Having one international definition for the "young adult" age group would be helpful for future data comparisons.

Based on the International Diabetes Federation Task Force on Epidemiology and Prevention, National Heart, Lung, and Blood Institute, American Heart Association, World Heart Federation, International Atherosclerosis Society, and the International Association for the Study of Obesity (IDF/NHLBI/AHA/WHF/IAS/IASO-2009) definition of MetS [21], the objective of the present study is to investigate the prevalence and the associated variables of MetS in Colombian collegiate students. In young adults, these factors may also contribute to the identification of the common and/or distinctive features of MetS, which can essentially aid in understanding the background of this disease and its components. Therefore, it is necessary to identify high-risk collegiate students in order to examine the associated factors for MetS. 


\section{Methods}

\subsection{Study Design and Sample Population}

We performed cross-sectional analyses of baseline data from participants in the FUPRECOL study (Association between Muscular Strength and Metabolic Risk Factors in Colombia), which focused on the associations between fitness, health, and non-communicable diseases. We have recently published a complete description of the FUPRECOL study design, methods, and primary outcomes for our current cohort [22,23]. A total of 890 volunteers (52.0\% female, mean age $=21.4$ (SD 3.3) years old) between the ages of 18 and 30 years, of low to middle socioeconomic status (SES: 1-4 on a scale of 1-6 defined by the Colombian government), were enrolled in public or private universities in the capital district of Bogota and Cali, Colombia. Inclusion criteria were: no self-reported history of inflammatory joint disease or neurological disorder; and not an athlete participating at an elite level. Volunteers were not compensated for their participation. Subjects with a medical or clinical diagnosis of a major systemic disease (including malignant conditions such as cancer), type 1 or 2 diabetes, high blood pressure, hypothyroidism/hyperthyroidism, a history of drug or alcohol abuse, regular use of multivitamins, or inflammatory (trauma, contusions) or infectious conditions, and $\geq 35 \mathrm{~kg} / \mathrm{m}^{2}$ body mass index (BMI) were also excluded from the study. The Institutional Ethics Committee in accordance with the latest version of the Declaration of Helsinki approved the study (UMB No. 01-1802-2013). After reading and signing an informed consent form in order to participate in the study, volunteers were given an appointment for a testing session at the university laboratories. The students who agreed to participate and who had signed the informed consent form were given appointments for the following procedures. Students were informed that their participation was voluntary with no penalty for not participating.

\subsection{Data Collection}

All data were collected at the same time in the morning, between 7:00 and 10:00 a.m. Body weight and height were measured following standard procedures and using an electronic scale (Tanita ${ }^{\circledR}$ BC544, Tokyo, Japan) and a mechanical stadiometer platform (Seca ${ }^{\circledR} 274$, Hamburg, Germany), respectively. BMI was calculated as body weight in kilograms divided by the square of the height in meters. BMI was classified as underweight, normal weight, overweight, or obese using the World Health Organization (WHO) criteria [24]. Waist circumference (WC) was measured at the midpoint between the last rib and the iliac crest using a tape measure (Ohaus ${ }^{\circledR}$ 8004-MA, Parsippany, NJ, USA). To classify WC, we used criterion-referenced health-related cut-points derived from a cross-sectional, Colombian national representative nutrition survey (ENSIN, 2010) [25]. In addition, we also calculated the waist-to-height ratio (WHtR). Ramírez-Vélez et al. [25] proposed a universal WHtR cut-off of $\geq 0.50$, which might identify early cardiovascular risk in Colombian adults. Lean mass $(\mathrm{kg})$ and body fat percentage $(\mathrm{BF} \%)$ were determined for bioelectrical impedance analysis (BIA) by Tanita BC- $418^{\circledR}$ (Tokyo, Japan). Measurements were made with the participant in a standing position with arms and legs lying parallel to the trunk and separated, so that the thighs were not touching. Before testing, participants were required to adhere to these BIA instructions: (i) to not eat or drink within $4 \mathrm{~h}$ of the test; (ii) to not consume caffeine or alcohol within $12 \mathrm{~h}$ of the test; (iii) to not take diuretics within seven days of the test; (iv) to not do physical exercise within $12 \mathrm{~h}$ of the test, and; (v) to urinate within $30 \mathrm{~min}$ of the test [26]. An electrical current of $50 \mathrm{kHz}$ was passed through the participant and the resistance and reactance were measured. To ensure data quality, the equipment was calibrated daily using a known calibration standard, in accordance with Ramírez-Velez et al.'s standard procedures [22]. The in vivo coefficient of variation assessed in our laboratory for adults use was $1.2 \%$ for $\mathrm{BF} \%$ [22]. The $\mathrm{BF} \%$ cut-offs chosen to perform the sensitivity and specificity comparisons were the values most frequently cited by international scientific literature $(20 \%-30 \% ; 30 \%-40 \%$, and $\geq 40 \%$ adiposity) by bioelectrical impedance analysis (BIA) in the Spanish population [27].

Blood pressure was measured twice from the left hand, via an Omron M6 Comfort (Omron ${ }^{\circledR}$ Healthcare Europe B.V., Hoofddorp, The Netherlands) while the participants were sitting still. 
The blood pressure monitor cuff was placed two to three finger-widths above the bend of the arm and a two-minute pause was allowed between the first and the second measurements. The mean blood pressure (MBP) was calculated using the following formula: $\mathrm{MBP}=$ (systolic blood pressure + $(2 \times$ diastolic blood pressure $)) / 3$.

Food consumption was assessed using the Kidmed questionnaire [28]. This tool consists of sixteen questions related to the principles of Mediterranean dietary patterns as reported previously [28]. In this study, we divided participants into two groups: less or equal to 8 points (ideal healthy diet), and less or equal to 7 points (non-ideal healthy diet).

\subsection{Laboratory Measurements}

After fasting for $12 \mathrm{~h}$, blood samples were obtained from a capillary sample at 6:30 am-7: $00 \mathrm{am}$. Participants were asked to not participate in any prolonged exercise for the $24 \mathrm{~h}$ prior to testing. The biochemical profile included: (1) the plasma lipid triglycerides, total cholesterol, high-density lipoprotein cholesterol (HDL-c), fasting glucose, and low-density lipoprotein cholesterol (LDL-c) (by enzymatic colorimetric methods). Inter-assay reproducibility (coefficient of variation) was determined from 80 replicate analyses of eight plasma pools over 15 days, and shown to be $2.6 \%, 2.0 \%$, $3.2 \%$, and $3.6 \%$ for triglycerides, total cholesterol, HDL-c, and LDL-c, respectively, and $1.5 \%$ for serum fasting glucose.

\subsection{Covariates}

A standardized questionnaire, (family, activity, nutrition, tobacco toxins, alcohol, sleep/stress, personality type, insight, career) FANTASTIC lifestyle, was used to collect comprehensive information about substance use via a personal interview with participants [23]. Alcohol drinkers and tobacco smokers were defined, respectively, as subjects who had consumed any alcoholic beverage $\geq 1$ times per week, and those who had smoked $\geq 10$ cigarettes per week, for at least six months. The determination of the physical activity (PA) levels was measured using the FANTASTIC questionnaire [23]. Although the FANTASTIC questionnaire only refers to PA participation in the previous week, subjects were also asked whether the pattern of PA reported in the FANTASTIC questionnaire was consistent with the previous seven days. PA was categorized as follows: insufficient: no PA practice ( $<150 \mathrm{~min} /$ week), OR sufficient PA: five or more days of moderate-intensity PA and/or walking, in combination or alone, at least $30 \mathrm{~min} /$ day, accumulating a minimum of $150 \mathrm{~min} /$ week according to WHO recommendations. The accuracy of information about substance use and PA levels obtained from questionnaires has been validated by different experiments and is described in detail elsewhere [23].

\subsection{Definition of the MetS}

MetS was defined as including $\geq 3$ of the following metabolic abnormalities [29-37]: $W C \geq 90 \mathrm{~cm}$ in men or $\geq 80 \mathrm{~cm}$ in women; HDL-c $<40 \mathrm{mg} / \mathrm{dL}$ in men or $<50 \mathrm{mg} / \mathrm{dL}$ in women; triglyceride $\geq 150 \mathrm{mg} / \mathrm{dL}$; fasting glucose $\geq 100 \mathrm{mg} / \mathrm{dL}$; systolic $\mathrm{BP}$ (SBP) $\geq 130 \mathrm{mmHg}$; and /or diastolic $\mathrm{BP}(\mathrm{DBP}) \geq 85 \mathrm{mmHg}$.

\subsection{Ethics Statement}

The sample size was calculated using Minitab software (version 16, Minitab Inc., State College, PA, USA) and was based on an expected prevalence of $4 \%$ MetS. At 0.80 power and a 0.05 significance level, a sample size of 600 would achieve a $1.60 \%$ margin of error for the survey of the college student population. Data analyses were carried out using IBM SPSS 21 (SPSS, Inc., Chicago, IL, USA). Descriptive statistics were computed and summarized; continuous variables were summarized using means and standard deviations (SD), and categorical variables using proportions (\%). The normality of the selected variables was verified using histograms and Q-Q plots. Differences were analysed using a $t$-student or chi-square test $\left(\chi^{2}\right)$ in order to explore sex-group differences. Binary logistic regression analysis was used to study the association between anthropometric (sex and age), body 
composition (levels of adiposity and WHtR), nutritional status (BMI categories), and nutrition profile (Mediterranean diet quality (low, medium, and high)), and the presence of MetS as the outcome variable, adjusted by smoking, alcohol intake, PA levels, and BF\%. Odds ratios were considered a confounder if they shifted the model in a constant direction with a proportional increase in the exposure level with a $p$ value $<0.10$. The level of statistical significance was established at $p<0.05$.

\section{Results}

\subsection{Descriptive Characteristics}

Table 1 shows the demographic descriptive statistics of the sample. The final sample had a mean age of $21.3 \pm 3.2$ (range 18.0-30.0) years and contained slightly more females (52\%). Women had lower levels of weight, height, WC, WHtR, lean mass, blood pressure, and triglycerides than men $(p<0.05)$. In women, the prevalence of overweight and obesity were $20.3 \%$ and $5.6 \%$, and these were $24.1 \%$ and $5.4 \%$ in men, respectively $(p<0.05)$, according to the WHO criteria, but women also showed a higher Mediterranean diet adherence (i.e., in level 2 and 3) compared to men $(p<0.001)$. The overall prevalence of MetS was 6.0\% (95\% CI $=4.5 \%$ to $7.6 \%)$, higher in men than women. Men were higher in three or more components of the MetS criteria than women $(9.0 \%$ vs. $3.0 \%, p<0.05)$. At least one MetS component was found in 331 participants (37.2\%); two MetS components were present in 151 participants $(17.0 \%)$; three MetS components were found in 39 participants $(4.4 \%)$; and four or more components of MetS were present in 14 participants (1.6\%) (see Table 1).

Table 1. Characteristics among a sample of college students from Colombia (mean (SD) or [frequencies]).

\begin{tabular}{|c|c|c|c|c|}
\hline & $\begin{array}{l}\text { All Participants } \\
\quad(n=890)\end{array}$ & $\begin{array}{l}\text { Women } \\
(n=463)\end{array}$ & $\begin{array}{c}\text { Men } \\
(n=427)\end{array}$ & $p$ Value \\
\hline Age (years) & $21.3(3.2)$ & $21.4(3.1)$ & $21.3(3.3)$ & 0.478 \\
\hline Weight (kg) & $64.2(12.5)$ & $58.8(10.0)$ & $69.8(12.4)$ & $<0.001$ \\
\hline Height (cm) & $165.8(9.0)$ & $159.8(6.1)$ & $172.4(6.7)$ & $<0.001$ \\
\hline Body mass index $\left(\mathrm{kg} / \mathrm{m}^{2}\right)$ & $23.2(3.7)$ & $23.0(3.7)$ & $23.4(3.6)$ & 0.097 \\
\hline \multicolumn{5}{|l|}{ Nutritional status by BMI [\%] * } \\
\hline Underweight & $29[3.3]$ & $16[3.5]$ & $13[3.0]$ & \multirow{4}{*}{0.588} \\
\hline Normal weight & $615[69.1]$ & $327[70.6]$ & $288[67.4]$ & \\
\hline Overweight & $197[22.1]$ & $94[20.3]$ & $103[24.1]$ & \\
\hline Obese & $49[5.5]$ & $26[5.6]$ & $23[5.4]$ & \\
\hline \multicolumn{5}{|l|}{ Body composition } \\
\hline Waist circumference $(\mathrm{cm})$ & $75.4(9.6)$ & $72.0(8.0)$ & $79.0(9.7)$ & $<0.001$ \\
\hline Waist-to-height ratio & $0.455(0.055)$ & $0.452(0.053)$ & $0.455(0.055)$ & 0.035 \\
\hline Body fat $(\%)$ & $21.6(8.8)$ & $26.8(7.2)$ & $16.0(6.6)$ & $<0.001$ \\
\hline Lean mass (kg) & $49.7(9.7)$ & $42.6(4.1)$ & $58.4(7.2)$ & $<0.001$ \\
\hline \multicolumn{5}{|l|}{ Level of adiposity [\%] * } \\
\hline$<20$ & $413[46.4]$ & $88[19.0]$ & $325[76.1]$ & \multirow{4}{*}{$<0.001$} \\
\hline 20 to 29 & $317[35.6]$ & $229[49.5]$ & $88[20.6]$ & \\
\hline 30 to 39 & 140 [15.7] & $127[27.4]$ & $13[3.0]$ & \\
\hline$>40$ & $20[2.2]$ & $19[4.1]$ & $1[0.2]$ & \\
\hline \multicolumn{5}{|l|}{ Mediterranean diet quality [\%] ${ }^{*, a}$} \\
\hline Low/medium/high & {$[54.8 / 36.2 / 8.9]$} & {$[42.8 / 42.8 / 14.5]$} & {$[61.0 / 32.9 / 6.1]$} & $<0.001$ \\
\hline \multicolumn{5}{|l|}{ Ethnic group [\%] * } \\
\hline Indigenous/Afro-Colombian/Mestizo & {$[2.2 / 25.3 / 72.5]$} & {$[2.0 / 32.2 / 65.8]$} & {$[2.4 / 21.7 / 75.9]$} & 0.052 \\
\hline \multicolumn{5}{|l|}{ Cardiovascular risk factors } \\
\hline Systolic blood pressure (mmHg) & $117.9(12.6)$ & $112.5(11.0)$ & $123.7(11.7)$ & $<0.001$ \\
\hline Diastolic blood pressure (mmHg) & $74.1(9.8)$ & $72.0(9.4)$ & $76.7(10.8)$ & $<0.001$ \\
\hline Mean blood pressure $(\mathrm{mmHg})$ & $88.7(9.7)$ & $85.5(8.8)$ & $92.4(9.7)$ & $<0.001$ \\
\hline Total cholesterol (mg/dL) & $142.2(33.6)$ & $148.7(34.4)$ & $135.4(31.3)$ & $<0.001$ \\
\hline Triglycerides (mg/dL) & $95.3(48.9)$ & $92.2(47.2)$ & $98.9(51.0)$ & 0.040 \\
\hline LDL-c $(\mathrm{mg} / \mathrm{dL})$ & $84.0(27.3)$ & $86.0(27.8)$ & $81.7(26.5)$ & 0.028 \\
\hline HDL-c (mg/dL) & $44.0(12.8)$ & $47.8(13.4)$ & $39.8(10.7)$ & $<0.001$ \\
\hline Glucose fasting (mg/dL) & $83.3(13.6)$ & $83.8(14.2)$ & $82.6(13.0)$ & 0.179 \\
\hline
\end{tabular}


Table 1. Cont.

\begin{tabular}{|c|c|c|c|c|}
\hline & $\begin{array}{l}\text { All Participants } \\
\quad(n=890)\end{array}$ & $\begin{array}{l}\text { Women } \\
(n=463)\end{array}$ & $\begin{array}{c}\text { Men } \\
(n=427)\end{array}$ & $p$ Value \\
\hline MetS prevalence [\%] ${ }^{*}$ & $53[6.0]$ & $14[3.0]$ & $39[9.0]$ & $<0.001$ \\
\hline \multicolumn{5}{|l|}{ Number of components $\mathrm{n}[\%]^{*}$} \\
\hline 0 & 355 [39.9] & $236[51.0]$ & 119 [27.9] & \multirow{5}{*}{$<0.001$} \\
\hline 1 & 331 [37.2] & 148 [32.0] & 183 [42.9] & \\
\hline 2 & 151 [17.0] & 65 [14.0] & 86 [20.1] & \\
\hline 3 & $39[4.4]$ & $11[2.4]$ & $28[6.6]$ & \\
\hline 4 or more & $14[1.6]$ & $3[0.6]$ & $11[2.4]$ & \\
\hline Tobacco ( $\geq 10$ cigarettes per week) [\%] ${ }^{*}$ & $60[6.7]$ & $22[4.7]$ & $30[7.2]$ & 0.349 \\
\hline Alcohol ( $\geq 1$ times per week) [\%] ${ }^{*}$ & 92 [10.1] & $42[9.0]$ & $50[11.7]$ & 0.041 \\
\hline PA levels ( $\geq 150$ min per week) [\%] * & $293[33.0]$ & $146[31.6]$ & $150[35.3]$ & $<0.001$ \\
\hline
\end{tabular}

Significant between-sex differences for Student's $t$-test or $\chi^{2 *} ;$ a Mediterranean diet quality: $(1) \leq 3$ points = poor diet quality; (2) 4-7 points = average diet quality; and (3) $\geq 8$ points = good diet quality (optimal Mediterranean diet style). BMI, body mass index; MetS, metabolic syndrome; PA, physical activity.

\subsection{Clinical Characteristics and Distribution by Metabolic Syndrome Status}

Participants with MetS had a significantly higher weight, body mass index, WC, waist to height ratio, body fat, blood pressure, and serum metabolic biomarkers $(p<0.001)$ (see Table 2). Furthermore, the most prevalent MetS variables in the sample were within men; over 23 years, with levels of adiposity of $20 \%-29 \%$, overweight status, a medium Mediterranean diet adherence, and Afro-Colombian ethnicity showed a higher MetS $(73.6 \%, 49.1 \%, 50.9 \%, 58.5 \%, 64.2 \%$, and $67.9 \%$, respectively).

Table 2. Anthropometric, body composition, cardiovascular risk factors, and associated factors by metabolic syndrome status.

\begin{tabular}{|c|c|c|c|}
\hline \multirow{2}{*}{ Characteristics } & \multicolumn{2}{|c|}{ Metabolic Syndrome Status } & \multirow[b]{2}{*}{$p$ Value } \\
\hline & No & Yes & \\
\hline \multicolumn{4}{|l|}{ Anthropometric and body composition } \\
\hline Age (years) & $21.4(3.2)$ & $23.1(4.0)$ & $<0.001$ \\
\hline Weight (kg) & $58.7(9.2)$ & $82.7(15.4)$ & $<0.001$ \\
\hline Height $(\mathrm{cm})$ & $163.7(8.6)$ & $170.5(9.1)$ & $<0.001$ \\
\hline Body mass index $\left(\mathrm{kg} / \mathrm{m}^{2}\right)$ & $21.8(2.6)$ & $28.4(4.3)$ & $<0.001$ \\
\hline Waist circumference $(\mathrm{cm})$ & $71.1(6.5)$ & $90.8(11.1)$ & $<0.001$ \\
\hline Waist to height ratio & $0.435(0.038)$ & $0.534(0.063)$ & $<0.001$ \\
\hline Body fat $(\%)$ & $20.8(7.6)$ & $27.9(8.4)$ & $<0.001$ \\
\hline Lean mass $(\mathrm{kg})$ & $59.4(10.4)$ & $45.3(7.4)$ & $<0.001$ \\
\hline \multicolumn{4}{|l|}{ Cardiovascular risk factors } \\
\hline Systolic blood pressure (mmHg) & $112.7(9.4)$ & $130.0(13.0)$ & $<0.001$ \\
\hline Diastolic blood pressure $(\mathrm{mmHg})$ & $70.8(6.7)$ & $84.5(14.2)$ & $<0.001$ \\
\hline Mean blood pressure $(\mathrm{mmHg})$ & $84.7(6.7)$ & $99.7(11.1)$ & $<0.001$ \\
\hline Total cholesterol (mg/dL) & $133.0(29.7)$ & $154.1(37.7)$ & $<0.001$ \\
\hline Triglycerides (mg/dL) & $79.0(25.2)$ & $180.3(75.4)$ & $<0.001$ \\
\hline LDL-c (mg/dL) & $85.7(30.4)$ & $87.4(29.3)$ & $<0.001$ \\
\hline HDL-c (mg/dL) & $52.3(9.9)$ & $31.7(7.5)$ & 0.125 \\
\hline Glucose fasting (mg/dL) & $79.8(12.0)$ & $92.1(16.1)$ & $<0.001$ \\
\hline \multicolumn{4}{|l|}{ Associated factors * } \\
\hline Women & $14[26.4]$ & $449[53.6]$ & \multirow{2}{*}{$<0.001$} \\
\hline Men & 39 [73.6] & $388[46.4]$ & \\
\hline \multicolumn{4}{|l|}{ Age group * } \\
\hline 18 to 19 years & 12 [22.6] & $306[36.6]$ & \multirow{3}{*}{$<0.001$} \\
\hline 20 to 22 years & $15[28.3]$ & $313[37.4]$ & \\
\hline Over 23 years & $26[49.1]$ & $218[26.0]$ & \\
\hline \multicolumn{4}{|l|}{ Level of adiposity $(\%)^{*}$} \\
\hline$<20$ & $8[15.1]$ & $405[48.4]$ & \multirow{4}{*}{0.002} \\
\hline 20 to 29 & $27[50.9]$ & $291[34.8]$ & \\
\hline 30 to 39 & 14 [26.4] & $125[14.9]$ & \\
\hline$>40$ & $4[7.5]$ & $16[1.9]$ & \\
\hline
\end{tabular}


Table 2. Cont.

\begin{tabular}{lccc}
\hline \multirow{2}{*}{ Characteristics } & \multicolumn{3}{c}{ Metabolic Syndrome Status } \\
\cline { 2 - 4 } & No & Yes & $p$ Value \\
\hline Nutritional status * & & & \\
\hline Underweight & $0[0.0]$ & $29[3.5]$ & \\
Normal & $6[11.3]$ & $609[72.8]$ & $<0.001$ \\
Overweight & $31[58.5]$ & $166[19.8]$ & \\
Obesity & $16[30.2]$ & $33[3.95$ & \\
\hline Mediterranean diet quality * & & & \\
\hline Low & $15[28.3]$ & $418[49.9]$ & \\
Medium & $34[64.2]$ & $346[41.3]$ & \\
High & $4[7.5]$ & $73[8.7]$ & \\
\hline Ethnic group * & & & \\
\hline Indigenous & $8[15.1]$ & $16[1.9]$ & \\
Afro-Colombian & $36[67.9]$ & $208[24.9]$ & \\
Mestizo & $9[17.0]$ & $613[73.2]$ & \\
\hline
\end{tabular}

Data are shown as (mean (SD) or [frequencies]). Significant between-sex differences for Student's $t$-test or $\chi^{2 *}$

\subsection{Factors Associated with Metabolic Syndrome}

Figure 1 shows the results from the logistic regression analysis. The predisposing factors for having a MetS included being male (OR $7.86(95 \% \mathrm{CI}=1.73$ to 35.72$)$ ), being over 23 years old (OR 3.70 (95\% CI $=1.39$ to 9.85$)$ ), having $20 \%-29 \%$ adiposity (OR $6.03(95 \% \mathrm{CI}=2.40$ to 15.14$)$ ), being overweight (OR $8.51(95 \% \mathrm{CI}=2.88$ to 25.20$)$ ), being obese (OR $66.58(95 \% \mathrm{CI}=13.54$ to 327.41$)$ ), and having an unhealthy waist-to-height ratio (OR $12.19(95 \% \mathrm{CI}=4.87$ to 30.49$)$ ).

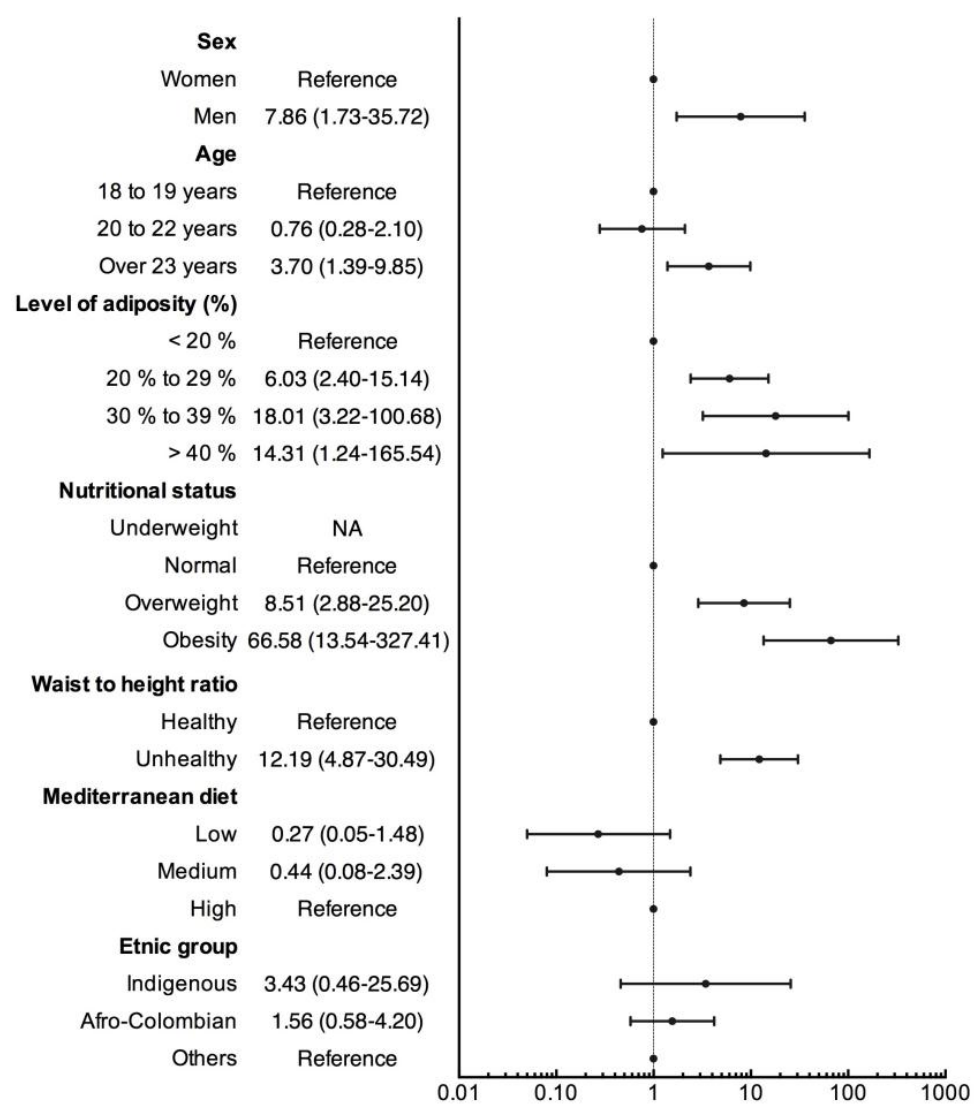

Figure 1. Factors associated with MetS among a sample of college students from Colombia. 


\section{Discussion}

The main finding of the present study was a MetS prevalence of $6 \%$, which is an intermediate value compared to those reported in local and international studies, ranging from $2 \%$ to $13 \%$ (29-38). For example, Dalleck et al. [34] reported a prevalence of $6.8 \%$ in university students with similar characteristics to those found in the present study. Ford et al. [35] conducted a cross-sectional study with adults aged 18-30 years in the United States and reported a similar MetS prevalence of 6.7\%, using the definition of the National Cholesterol Education Program-Adult Treatment Panel III of the United States.

The rates found in university contexts by the present study were much higher than those found by the following authors: Huang et al. [29] in 163 students aged 18-24 years in Kansas, United States, (0.6\%); de Freitas et al. [30] in 702 Brazilian university students (1.7\%); Fernandes et al. [31] in 189 students aged 18-24 years (3.7\%); Yen et al. [32] in 8226 students with a mean age of $19.2 \pm 2.3$ years (4.6\%); and Burke et al. [33] in 1701 students aged 18-24 years, who were enrolled in an introductory nutrition course and had met the age requirements of the University of New Hampshire's Young Adult Health Risk Screening Initiative (4.9\%). On the other hand, our rates were lower than those found by Ruano et al. [36] in 796 Spanish students aged 17-25 years (7.5\%), and Mattsson et al. [38] in 2182 healthy young adults (1007 men and 175 women) aged 24-39 years $(13 \%)$. Clearly, the prevalence of MetS could differ between studies depending on the MetS cluster used, design method, and target population. In this study, we have used the International Diabetes Federation (IDF) and American Heart Association (AHA) and the National Heart, Lung, and Blood Institute (NHLBI) joint statement, as it was an international attempt to harmonize the definition of MetS; central obesity is not an obligatory component of this definition and it is ethnic specific.

The criterion for MetS that had the highest prevalence (40.7\%) was low HDL-c. Previous studies have described the prevalence of low HDL-c with values between $20.1 \%$ and $47.8 \%$ [31,34,39]. From a preventive perspective, HDL-c could be an early marker for the development of metabolic disorders [40] and, therefore, strategies such as weight control, caloric intake reduction, and regular physical exercise should be encouraged in university contexts.

High blood pressure is an important risk factor for the main cardiovascular disorders, such as ischemic heart disease and stroke [41]. Several observational studies have described the frequent association between high blood pressure values and MetS, however, the interrelationship with obesity or other risk situations, such as alterations in glucose metabolism, suggests that the basis of this epidemiological association could be related to common physiopathological implications [42,43].

In the present study, we demonstrated that the elevation of blood pressure was the second most prevalent criterion, with a frequency of $20.9 \%$. This result was similar to that reported by the The National Health and Nutrition Examination Survey (NHANES) (2003-2006). This finding is important because most longitudinal studies have agreed that a high blood pressure level is one of the most prevalent criteria [44], and individuals diagnosed with high blood pressure have high MetS prevalence [45].

When we compared sex-related differences, it was noted that men had a MetS prevalence of $9.1 \%$, which was three times higher than the prevalence observed in women (3\%). The occurrence of MetS among men was significant (OR $=3.22 ; 95 \% \mathrm{CI}=1.76$ to 6.03$)$. This result is opposed to that reported by Abda et al. [46], who found that there was greater occurrence of MetS in women $(\mathrm{OR}=2.86$; 95\% $\mathrm{CI}=1.51$ to 5.42); however, our findings were in line with the data reported by de Freitas et al. [30] in Brazil, who observed that the prevalence of MetS in men was twice as high than in women. Barbieri et al. [47] reported that the prevalence of MetS was 2.20 times higher in men than in women (10.7 vs. 4.2\%). On the other hand, Ramírez-Vélez et al. [3] conducted a local study with Colombian youth and observed a slightly higher prevalence in girls than in boys when MetS was estimated using Ferranti's criteria (12\% vs. 9.8\%). This same result was reported by Fernandes et al. [31] in the United States population. These authors found higher rates of MetS in women than in men (4.7\% vs. 1.6\%). Similar results were observed by Park et al. [48] in Korean young adults aged 20-39 years. 
With respect to age, we observed a significantly increased prevalence of MetS, ranging from 3.8\% in the group of individuals aged $18-19$ years to $11 \%$ in the group of individuals aged 23 years or older. In fact, it has been reported that the risk of MetS and the related criteria increase with age [49]. In the present study, we observed that university students aged over 23 years had a greater occurrence of MetS (OR $=3.04 ; 95 \% \mathrm{CI}=1.50$ to 6.16), a result that was in line with rates found in Arab women [50]. These authors suggested that the risk of MetS increases after 23 years of age $(\mathrm{OR}=2.96 ; 95 \% \mathrm{CI}=1.31$ to 6.06). Dhaheri et al. [20] reported a similar tendency in a cohort of the study "Young Female Emirati Adults", in which the prevalence of MetS ranged from 4.1\% among university students aged 17 to 19 years, to $11.3 \%$ among students aged $23-25$ years.

It has been reported that central obesity is one of the main characteristics of MetS, particularly due to increased values of free fatty acids in the blood and the inhibition of insulin action in peripheral tissues [50-52]. In the present study, we observed $10.7 \%$ of central obesity in the population assessed, a value that increased to $56.6 \%$ in individuals with MetS. This risk factor was also described as the most prevalent metabolic abnormality in the "Young Adult Health in Saudi Arabia" study [53], and by Park et al. [48] in Korean young adults aged 20-39 years.

The risk of MetS in overweight and obese individuals was $49.2(95 \% \mathrm{CI}=18.07$ to 133.97$)$ and $\mathrm{OR}=49.12(95 \% \mathrm{CI}=18.07$ to 133.97$)$, respectively. This result was in line with the findings of the following authors: Dhaheri et al. [50] in university women from the United Arab Emirates $(\mathrm{OR}=11.19 ; 95 \% \mathrm{CI}=3.06$ to 40.86$)$; Ismail in adult Indians [54] $(\mathrm{OR}=7.17 ; 95 \% \mathrm{CI}=1.73$ to 19.7$)$; and Ramírez-Velez et al. [3] in Colombian children and adolescents (OR $=1.69 ; 95 \% \mathrm{CI}=1.13$ to 2.53$)$. Similarly, we observed that overweight increased the risk of MetS (SM) $(\mathrm{OR}=18.95 ; 95 \% \mathrm{CI}=7.78$ to 46.19). This result was similar to that reported by Abda et al. [46] in Ethiopian adults using the National Cholesterol Education Program-Adult Treatment Panel III (OR = 5.49; 95\% CI = 2.90 to 1054).

Ethnicity has been associated with the development of MetS worldwide [55]. According to the definition of the National Cholesterol Education Program-Adult Treatment Panel III of the United States, the prevalence of MetS in adults was: 32\% in Hispanic Americans; $22 \%$ in African Americans; and $24 \%$ in European Americans [56]. Similarly, a prevalence of $24 \%$ in Caucasian individuals was reported in the Framingham Study, and a prevalence of 31\% in individuals of Mexican origin was reported in the San Antonio Heart Study [57]. However, South America has no standards for the diagnosis of MetS. In this respect, Ramírez-Vélez et al. [58,59] reported a high prevalence of micronutrient and vitamin deficiencies combined with the double burden of nutritional disorders in indigenous and Afro-Colombian populations, a condition related to metabolic disorders as described in the present study. When we grouped the individuals by ethnicity, the indigenous and Afro-Colombian individuals exhibited a higher prevalence of MetS, with values of $20 \%$ and $8 \%$, respectively.

Previous studies have reported that several alterations in body composition and metabolic pathways could be in part explained by genetic and ethnic factors [60]. For example, the HDL-c metabolism has shown the highest heritability estimates (between $50 \%$ and $60 \%$ ), whereas systolic blood pressure showed the lowest heritability estimates (between $6 \%$ and $18 \%$ ). Much of the risk of MetS associated with ethnicity can be explained by the change in steroid hormone levels and the metabolism of carbohydrates and lipids [61]. An increase in total fat and the distribution of central fat, resulting from alterations in hormones, such as leptin, adiponectin, resistin, and estrogen, which are mediators of MetS, has been reported in indigenous and Afro-American populations. The increased susceptibility of Africans when exposed to lifestyle abnormalities, such as high salt intake, shows the collision between genes adapted to a warm climate and the "modern" lifestyle [62].

Studies based on adherence to the Mediterranean diet reported controversial results [63-66]. The AHA includes diet behavior as one of seven health behaviors to track for the 2020 Strategic Impact Goals [63] and more recently, has been evaluated for the prevention and treatment of MetS [64]. Consistent with our findings, we did not detect a significant effect of healthy diets on the prevalence of MetS [65]. Babio et al. [66] showed a positive association between adherence to the Mediterranean diet and a lower odds ratio of having MetS in a population with a high risk of cardiovascular disease, 
while Tzima et al. [67] observed a modest, not-significant association between insulin resistance and adherence to the Mediterranean diet in overweight/obese subjects. Overall, the adoption of the Mediterranean diet has been demonstrated to reduce MetS by $66 \%$; moreover, this effect seems to be independent of weight loss [66].

One limitation of the present study was the lack of information about physical fitness levels (e.g., cardiorespiratory fitness or musculoskeletal fitness) and family history of cardiometabolic diseases or non-alcoholic fatty liver disease (NAFLD) detection, which suggests the need for more robust analyses. Another limitation was the cross-sectional design of the study, which did not allow a "cause-effect" relationship to be established. These and other questions deserve further investigation by future well-designed longitudinal studies. On the other hand, the relevance of the present study lies in the fact that it is the first study to assess MetS prevalence in a Colombian university population.

\section{Conclusions}

In summary, we found that the prevalence of MetS and its components was substantial in the studied population. Dyslipidemia, followed by central obesity and high blood pressure levels, were the most frequent components of MetS. Being male, over 23 years old, overweight or obese, and a unhealthy WHtR were significantly associated with MetS. Interventions that take into account nutritional elements and physical activities are recommended, because they can counteract this important health problem in university contexts.

Acknowledgments: This study was part of the project entitled "Body Adiposity Index and Biomarkers of Endothelial and Cardiovascular Health in Adults", which was funded by Centre for Studies on Measurement of Physical Activity, School of Medicine and Health Sciences, Universidad del Rosario (Code N ${ }^{\circ}$ FIUR DN-BG001) and Institución Universitaria Antonio José Camacho (Code $\mathrm{N}^{\circ}$ PI-0516). The funder had no role in the study design, data collection, data analysis and interpretation, preparation of the manuscript, or decision to publish.

Author Contributions: Robinson Ramírez-Vélez, Katehrine González-Ruíz, and Jorge Enrique Correa-Bautista conceived, designed the study, and analyzed the data; Daniel Humberto Prieto-Benavidez, Javier Martinez-Torres, Hector Reynaldo Tríana-Reina, Hugo Alejandro Carrillo, Jeison Alexander Ramos-Sepúlveda, Emilio Villa-González, and Antonio García-Hermoso analyzed the data and wrote the paper. All authors read and approved the final manuscript.

Conflicts of Interest: The authors declare no conflict of interest.

\section{Abbreviations}

The following abbreviations are used in this manuscript:

$\begin{array}{ll}\text { BF\% } & \text { body fat percentage } \\ \text { BIA } & \text { Bioelectrical impedance analysis } \\ \text { BMI } & \text { body mass index } \\ \text { DBP } & \text { diastolic blood pressure } \\ \text { ENSIN, 2010 } & \text { Colombian national representative nutrition survey } \\ \text { FUPRECOL study } & \text { Association between Muscular Strength and Metabolic Risk Factors in Colombia } \\ \text { HDL-c } & \text { low high-density lipoprotein cholesterol } \\ \text { IDF } & \text { International Diabetes Federation } \\ \text { LDL-c } & \text { low-density lipoprotein cholesterol } \\ \text { MetS } & \text { metabolic syndrome } \\ \text { NHANES } & \text { National Health and Nutrition Examination Survey } \\ \text { SBP } & \text { systolic blood pressure } \\ \text { WC } & \text { waist circumference } \\ \text { WHtR } & \text { waist-to-height ratio }\end{array}$

\section{References}

1. Zimmet, P.; Magliano, D.; Matsuzawa, Y.; Alberti, G.; Shaw, J. The metabolic syndrome: A global public health problem and a new definition. J. Atheroscler. Thromb. 2005, 12, 295-300. [CrossRef] [PubMed] 
2. López-Jaramillo, P.; Sánchez, R.A.; Díaz, M.; Cobos, L.; Bryce, A.; Parra-Carrillo, J.Z.; Lizcano, F.; Lanas, F.; Sinay, I.; Sierra, I.D.; et al. Nombre del Grupo de Expertos de Latinoamérica. Latin American consensus on hypertension in patients with diabetes type 2 and metabolic syndrome. Clin. Investig. Arterioscler. 2014, 26, 85-103. [CrossRef] [PubMed]

3. Ramírez-Vélez, R.; Anzola, A.; Martinez-Torres, J.; Vivas, A.; Tordecilla-Sanders, A.; Prieto-Benavides, D.; Izquierdo, M.; Correa-Bautista, J.E.; Garcia-Hermoso, A. Metabolic Syndrome and Associated Factors in a Population-Based Sample of Schoolchildren in Colombia: The FUPRECOL Study. Metab. Syndr. Relat. Disord. 2016, 14, 455-462. [CrossRef] [PubMed]

4. Grundy, S.M.; Cleeman, J.I.; Daniels, S.R.; Donato, K.A.; Eckel, R.H.; Franklin, B.A.; Gordon, D.J.; Krauss, R.M.; Savage, P.J.; Smith, S.C.; et al. Diagnosis and management of the metabolic syndrome: An American Heart Association/National Heart, Lung, and Blood Institute Scientific Statement. Circulation 2005, 112, 2735-2752. [CrossRef] [PubMed]

5. Arguelles, W.; Llabre, M.M.; Sacco, R.L.; Penedo, F.J.; Carnethon, M.; Gallo, L.C.; Lee, D.J.; Catellier, D.J.; González, H.M.; Holub, C.; et al. Characterization of metabolic syndrome among diverse Hispanics/Latinos living in the United States: Latent class analysis from the Hispanic Community Health Study/Study of Latinos (HCHS/SOL). Int. J. Cardiol. 2015, 184, 373-379. [CrossRef] [PubMed]

6. Wildman, R.P.; Muntner, P.; Reynolds, K.; McGinn, A.P.; Rajpathak, S.; Wylie-Rosett, J.; Sowers, M.R. The obese without cardiometabolic risk factor clustering and the normal weight with cardiometabolic risk factor clustering: Prevalence and correlates of 2 phenotypes among the US population (NHANES 1999-2004). Arch. Intern. Med. 2008, 168, 1617-1624. [CrossRef] [PubMed]

7. Daviglus, M.L.; Pirzada, A.; Talavera, G.A. Cardiovascular disease risk factors in the Hispanic/Latino population: Lessons from the Hispanic Community Health Study/Study of Latinos (HCHS/SOL). Prog. Cardiovasc. Dis. 2014, 57, 230-236. [CrossRef] [PubMed]

8. Llabre, M.M.; Arguelles, W.; Schneiderman, N.; Gallo, L.C.; Daviglus, M.L.; Chambers, E.C.; Sotres-Alvarez, D.; Chirinos, D.A.; Talavera, G.A.; Castaneda, S.F.; et al. Do all components of the metabolic syndrome cluster together in U.S. Hispanics/Latinos? Results from the Hispanic Community Health study/Study of Latinos. Ann. Epidemiol. 2015, 25, 480-485. [CrossRef] [PubMed]

9. Zheng, R.; Yang, M.; Bao, Y.; Li, H.; Shan, Z.; Zhang, B.; Liu, J.; Lv, Q.; Wu, O.; Zhu, Y.; et al. Prevalence and Determinants of Metabolic Health in Subjects with Obesity in Chinese Population. Int. J. Environ. Res. Public Health 2015, 12, 13662-13677. [CrossRef] [PubMed]

10. Elks, C.M.; Francis, J. Central adiposity, systemic inflammation, and the metabolic syndrome. Curr. Hypertens. Rep. 2010, 12, 99-104. [CrossRef] [PubMed]

11. Kapourchali, F.R.; Surendiran, G.; Goulet, A.; Moghadasian, M.H. The Role of Dietary Cholesterol in Lipoprotein Metabolism and Related Metabolic Abnormalities: A Mini-review. Crit. Rev. Food Sci. Nutr. 2016, 56, 2408-2415. [CrossRef] [PubMed]

12. Wu, S.; Fisher-Hoch, S.P.; Reininger, B.; McCormick, J.B. Recommended Levels of Physical Activity Are Associated with Reduced Risk of the Metabolic Syndrome in Mexican-Americans. PLoS ONE 2016, 11, e0152896. [CrossRef] [PubMed]

13. Hwang, H.J.; Kim, S.H. The association among three aspects of physical fitness and metabolic syndrome in a Korean elderly population. Diabetol. Metab. Syndr. 2015, 7, 112. [CrossRef] [PubMed]

14. Lopez-Jaramillo, P.; Lahera, V.; Lopez-Lopez, J. Epidemic of cardiometabolic diseases: A Latin American point of view. Ther. Adv. Cardiovasc. Dis. 2011, 5, 119-131. [CrossRef] [PubMed]

15. Lopez-Jaramillo, P.; Gomez-Arbelaez, D.; Sotomayor-Rubio, A.; Mantilla-Garcia, D.; Lopez-Lopez, J. Maternal undernutrition and cardiometabolic disease: A Latin American perspective. BMC Med. 2015, 13, 41. [CrossRef] [PubMed]

16. Ramírez-Vélez, R.; Suaréz-Ortegón, M.F.; Aguilar de Plata, A.C. Association between adiposity and cardiovascular risk factors in infants pre-pubertal. Endocrinol. Nutr. 2011, 58, 457-463. [CrossRef] [PubMed]

17. Fonseca-Camacho, D.F.; Hernández-Fonseca, J.M.; González-Ruíz, K.; Tordecilla-Sanders, A.; Ramírez-Vélez, R. A better self-perception of physical fitness is associated with lower prevalence of metabolic syndrome and its components among university students. Nutr. Hosp. 2014, 31, 1254-1263. [PubMed]

18. González-Ruíz, K.; Correa-Bautista, J.E.; Ramírez-Vélez, R. Body adiposity and its relationship of metabolic syndrome components in Colombian adults. Nutr. Hosp. 2015, 32, 1468-1475. [PubMed] 
19. Ramírez-Vélez, R.; Triana-Reina, H.R.; Carrillo, H.A.; Ramos-Sepúlveda, J.A.; Rubio, F.; Poches-Franco, L.; Rincón-Párraga, D.; Meneses-Echávez, J.F.; Correa-Bautista, J.E. A cross-sectional study of Colombian University students' self-perceived lifestyle. SpringerPlus 2015, 4, 289. [CrossRef] [PubMed]

20. Al Dhaheri, A.S.; Mohamad, M.N.; Jarrar, A.H.; Ohuma, E.O.; Ismail, L.C.; Al Meqbaali, F.T.; Souka, U.; Shah, S.M. A Cross-Sectional Study of the Prevalence of Metabolic Syndrome among Young Female Emirati Adults. PLoS ONE 2016, 11, e0159378. [CrossRef] [PubMed]

21. Alberti, K.G.; Eckel, R.H.; Grundy, S.M.; Zimmet, P.Z.; Cleeman, J.I.; Donato, K.A.; Fruchart, J.C.; James, W.P.; Loria, C.M.; Smith, S.C., Jr.; et al. Harmonizing the metabolic syndrome: A joint interim statement of the International Diabetes Federation Task Force on Epidemiology and Prevention; National Heart, Lung, and Blood Institute; American Heart Association; World Heart Federation; International Atherosclerosis Society; and International Association for the Study of Obesity. Circulation 2009, 120, 1640-1645. [PubMed]

22. Ramírez-Vélez, R.; Correa-Bautista, J.E.; Lobelo, F.; Izquierdo, M.; Alonso-Martínez, A.; Rodríguez-Rodríguez, F.; Cristi-Montero, C. High muscular fitness has a powerful protective cardiometabolic effect in adults: Influence of weight status. BMC Public Health 2016, 16, 1012. [CrossRef] [PubMed]

23. Ramírez-Vélez, R.; Triana-Reina, H.R.; Carrillo, H.A.; Ramos-Sepúlveda, J.A. Percepción de barreras para la práctica de la actividad física y obesidad abdominal en universitarios de Colombia. Nutr. Hosp. 2016, 33, 1317-1323. [CrossRef] [PubMed]

24. World Health Organization. Obesity: Preventing and Managing the Global Epidemic. Report of a WHO Consultation on Obesity, 3-5 June 1997, WHO/NUT/NCD/98.1 1997; WHO: Geneva, Switzerland, 1997.

25. Ramírez-Vélez, R.; Correa-Bautista, J.E.; Martínez-Torres, J.; Méneses-Echavez, J.F.; González-Ruiz, K.; González-Jiménez, E.; Schmidt-RioValle, J.; Lobelo, F. LMS tables for waist circumference and waist-height ratio in Colombian adults: Analysis of nationwide data 2010. Eur. J. Clin. Nutr. 2016, 70, 1189-1196. [CrossRef] [PubMed]

26. Jaffrin, M.Y. Body composition determination by bioimpedance: An update. Curr. Opin. Clin. Nutr. Metab. Care 2009, 12, 482-486. [CrossRef] [PubMed]

27. Johnson Stoklossa, C.A.; Forhan, M.; Padwal, R.S.; Gonzalez, M.C.; Prado, C.M. Practical Considerations for Body Composition Assessment of Adults with Class II/III Obesity Using Bioelectrical Impedance Analysis or Dual-Energy X-Ray Absorptiometry. Curr. Obes. Rep. 2016, 5, 389-396. [CrossRef] [PubMed]

28. Flores Navarro-Pérez, C.; González-Jiménez, E.; Schmidt-RioVilla, J.; Meneses-Echávez, J.F.; Correa-Bautista, J.E.; Correa-Rodríguez, M.; Ramírez-Vélez, R. Nivel y estado nutricional en niños y adolescentes de Bogotá, Colombia. Estudio FUPRECOL. Nutr. Hosp. 2016, 33, 915-922. [CrossRef] [PubMed]

29. Huang, T.T.K.; Kempf, A.M.; Strother, M.L.; Li, C.; Lee, R.E.; Harris, K.J.; Kaur, H. Overweight and components of the metabolic syndrome in college students. Diabetes Care 2004, 27, 3000-3001. [CrossRef] [PubMed]

30. De Freitas, R.J.; de Araújo, M.F.; Marinho, N.B.; de Vasconcelos, H.C.; Lima, A.C.; Pereira, D.C.; Almeida, P.C.; Zanetti, M.L.; Damasceno, M.M. Prevalence of the metabolic syndrome and its individual components in Brazilian college students. J. Clin. Nurs. 2013, 22, 1291-1298. [CrossRef] [PubMed]

31. Fernandes, J.; Lofgren, I. Prevalence of metabolic syndrome and individual criteria in college students. J. Am. Coll. Health 2011, 59, 313-321. [CrossRef] [PubMed]

32. Yen, S.; Chiu, T.; Lin, Y.; Lee, Y.; Lee, L.; Huang, K. Obesity and hepatitis B infection are associated with increased risk of metabolic syndrome in university freshmen. Int. J. Obes. 2008, 32, 474-480. [CrossRef] [PubMed]

33. Burke, J.; Reilly, R.; Morrell, J.; Lofgren, I. The University of New Hampshire's Young Adult Health Risk Screening Initiative. J. Am. Diet. Assoc. 2009, 109, 1751-1758. [CrossRef] [PubMed]

34. Dalleck, L.; Kjelland, E. The prevalence of metabolic syndrome and metabolic syndrome risk factors in college-aged students. Am. J. Health Promot. 2012, 27, 37-42. [CrossRef] [PubMed]

35. Ford, E.; Giles, W.; Mokdad, A. Increasing prevalence of the metabolic syndrome among U.S. adults. Diabetes Care 2004, 27, 2444-2449. [CrossRef] [PubMed]

36. Ruano Nieto, C.; Melo Pérez, J.; Mogrovejo Freire, L.; De Paula Morales, K.; Espinoza Romero, C. Prevalence of metabolic syndrome and associated risk factors in ecuadorian university students. Nutr. Hosp. 2015, 31, 1474-1481.

37. Cardoso, V.; Barbieri, M.; Bettiol, H.; Silva, A.; Santos, C. Metabolic syndrome in young adults: When does the problem arise? Pediatr. Res. 2008, 63, 452. 
38. Mattsson, N.; Rönnemaa, T.; Juonala, M.; Viikari, J.; Raitakari, O. The prevalence of the metabolic syndrome in young adults. The Cardiovascular Risk in Young Finns Study. J. Intern. Med. 2007, 261, 159-169. [CrossRef] [PubMed]

39. De Ferranti, S.; Gauvreau, K.; Ludwig, D.; Neufeld, E.; Newburger, J.; Rifai, N. Prevalence of the metabolic syndrome in American adolescents: Findings from the Third National Health and Nutrition Examination Survey. Circulation 2004, 110, 2494-2497. [CrossRef] [PubMed]

40. Siddiqi, H.; Kiss, D.; Rader, D. HDL-cholesterol and cardiovascular disease: Rethinking our approach. Curr. Opin. Cardiol. 2015, 30, 536-542. [CrossRef] [PubMed]

41. Regitz-Zagrosek, V.; Kararigas, G. Mechanistic Pathways of Sex Differences in Cardiovascular Disease. Physiol. Rev. 2017, 97, 1-37. [CrossRef] [PubMed]

42. Boned Ombuena, P.; Rodilla Sala, E.; Costa Muñoz, J.; Pascual Izuel, J. Hipertensión arterial y prediabetes. Med. Clin. 2016, 147, 387-392. [CrossRef] [PubMed]

43. Scuteri, A.; Franco, O.; Völzke, H.; Shin, M.; Kweon, S.; Rietzschel, E.; Nilsson, P.M. The relationship between the metabolic syndrome and arterial wall thickness: A mosaic still to be interpreted. Atherosclerosis 2016, 255, 11-16. [CrossRef] [PubMed]

44. Alexander, C.; Landsman, P.; Teutsch, S.; Haffner, S. NCEP-defined metabolic syndrome, diabetes, and prevalence of coronary heart disease among NHANES III participants age 50 years and older. Diabetes 2003, 52, 1210-1214. [CrossRef] [PubMed]

45. Schillaci, G.; Pirro, M.; Vaudo, G.; Gemelli, F.; Marchesi, S.; Porcellati, C.; Mannarino, E. Prognostic value of the metabolic syndrome in essential hypertension. J. Am. Coll. Cardiol. 2004, 43, 1817-1822. [CrossRef] [PubMed]

46. Abda, E.; Hamza, L.; Tessema, F.; Cheneke, W. Metabolic syndrome and associated factors among outpatients of Jimma University Teaching Hospital. Diabetes Metab. Syndr. Obes. 2016, 9, 47-53. [PubMed]

47. Barbieri, M.A.; Bettiol, H.; Silva, A.A.M.; Cardoso, V.C.; Simões, V.M.F.; Gutierrez, M.R.P.; Castro, J.A.S.; Vianna, E.S.O.; Foss, M.C.; Dos Santos, J.E.; et al. Health in early adulthood: The contribution of the 1978/79 Ribeirão Preto birth cohort. Braz. J. Med. Biol. Res. 2008, 39, 1041-1055. [CrossRef]

48. Park, J.; Mendoza, J.; O’Neil, C.; Hilmers, D.; Liu, Y.; Nicklas, T. A comparison of the prevalence of the metabolic syndrome in the United States (US) and Korea in young adults aged 20 to 39 years. Asia Pac. J. Clin. Nutr. 2008, 17, 471-482. [PubMed]

49. Khang, A.; Ku, E.; Kim, Y.; Roh, E.; Bae, J.; Oh, T.; Kim, S.W.; Shin, C.S.; Kim, S.Y.; Kim, J.H. Sex differences in the prevalence of metabolic syndrome and its components in hypopituitary patients: Comparison with an age- and sex-matched nationwide control group. Pituitary 2016, 19, 573-581. [CrossRef] [PubMed]

50. Roos, V.; Elmståhl, S.; Ingelsson, E.; Sundström, J.; Ärnlöv, J.; Lind, L. Metabolic Syndrome Development During Aging with Special Reference to Obesity without the Metabolic Syndrome. Metab. Syndr. Relat. Disord. 2017, 15, 36-43. [CrossRef] [PubMed]

51. Tao, Y.; Yu, J.; Tao, Y.; Pang, H.; Yu, Y.; Yu, Y.; Jin, L. Comparison of the Combined Obesity Indices to Predict Cardiovascular Diseases Risk Factors and Metabolic Syndrome in Northeast China. Int. J. Environ. Res. Public Health 2016, 13, 801. [CrossRef] [PubMed]

52. Mongraw-Chaffin, M.; Foster, M.C.; Kalyani, R.R.; Vaidya, D.; Burke, G.L.; Woodward, M.; Anderson, C.A. Obesity Severity and Duration Are Associated With Incident Metabolic Syndrome: Evidence Against Metabolically Healthy Obesity From the Multi-Ethnic Study of Atherosclerosis. J. Clin. Endocrinol. Metab. 2016, 101, 4117-4124. [CrossRef] [PubMed]

53. Abolfotouh, M.; Al-Alwan, I.; Al-Rowaily, M. Prevalence of Metabolic Abnormalities and Association with Obesity among Saudi College Students. Int. J. Hypertens. 2012, 2012, 819726. [CrossRef] [PubMed]

54. Ismail, I.; Azeez, K.; Antomy, A.; Kunnummal, S. Metabolic syndrome and its associated factors among the adult population residing in Kannavam tribal area of Kannur District, Kerala. Trop. J. Med. Res. 2016, 19, 36-41. [CrossRef]

55. Ikram, U.Z.; Snijder, M.B.; Agyemang, C.; Schene, A.H.; Peters, R.J.; Stronks, K.; Kunst, A.E. Perceived Ethnic Discrimination and the Metabolic Syndrome in Ethnic Minority Groups: The Healthy Life in an Urban Setting Study. Psychosom. Med. 2017, 79, 101-111. [CrossRef] [PubMed]

56. Lin, H.-F.; Boden-Albala, B.; Juo, S.H.; Park, N.; Rundek, T.; Sacco, R.L. Heritabilities of the metabolic syndrome and its components in the Northern Manhattan Family Study. Diabetologia 2005, 48, 2006-2012. [CrossRef] [PubMed] 
57. Cossrow, N.; Falkner, B. Race/ethnic issues in obesity and obesity-related comorbidities. J. Clin. Endocrinol. Metab. 2004, 89, 2590-2594. [CrossRef] [PubMed]

58. Ramírez-Velez, R.; Correa-Bautisita, J.; Martínez-Torres, J.; Meneses-Echávez, J.; Lobelo, F. Vitamin B12 concentrations in pregnant Colombian women: Analysis of nationwide data 2010. BMC Pregnancy Childbirth 2016, 16, 26. [CrossRef] [PubMed]

59. Ramírez-Vélez, R.C.B.J.; Martínez-Torres, J.; Meneses-Echávez, J.; Lobelo, F. Vitamin B12 concentration and its association with sociodemographic factors in Colombian children: Findings from the 2010 National Nutrition Survey. Nutrition 2016, 32, 255-259. [CrossRef] [PubMed]

60. Young, J.H.; Chang, Y.-P.C.; Kim, J.; Chretien, J.-P.; Klag, M.J.; Levine, M.A.; Ruff, C.B.; Wang, N.-Y.; Chakravarti, A.; Przeworski, M. Differential susceptibility to hypertension is due to selection during the out-of-Africa expansion. PLoS Genet. 2015, 1, e82.

61. Di Rienzo, F.A.; Hudson, R.R. An evolutionary framework for common diseases: The ancestral-susceptibility model. Trends Genet. 2005, 21, 596-601. [CrossRef] [PubMed]

62. Pollex, R.L.; Hegele, R.A. Genetic determinants of the metabolic syndrome. Nat. Clin. Pract. Cardiovasc. Med. 2006, 3, 482-489. [CrossRef] [PubMed]

63. Lloyd-Jones, D.M.; Hong, Y.; Labarthe, D.; Mozaffarian, D.; Appel, L.J.; Van Horn, L.; Greenlund, K.; Daniels, S.; Nichol, G.; Tomaselli, G.F.; et al. Defining and setting national goals for cardiovascular health promotion and disease reduction: The American Heart Association's strategic impact goal through 2020 and beyond. Circulation 2010, 121, 586-613. [CrossRef] [PubMed]

64. Babio, N.; Toledo, E.; Estruch, R.; Ros, E.; Martinez-Gonzalez, M.A.; Castaner, O.; Bullo, M.; Corella, D.; Aros, F.; Gomez-Gracia, E.; et al. PREDIMED Study Investigators Mediterranean diets and metabolic syndrome status in the PREDIMED randomized trial. Can. Med. Assoc. J. 2014, 186, E649-E657. [CrossRef] [PubMed]

65. InterAct Consortium. Mediterranean diet and type 2 diabetes risk in the European Prospective Investigation into Cancer and Nutrition (EPIC) study. Diabetes Care 2011, 34, 1913-1918.

66. Babio, N.; Bulló, M.; Basora, J.; Martínez-González, M.A.; Fernández-Ballart, J.; Márquez-Sandoval, F.; Molina, C.; Salas-Salvadó, J. Nureta-PREDIMED Investigators. Nutr. Metab. Cardiovasc. Dis. 2009, 19, 563-570. [CrossRef] [PubMed]

67. Tzima, N.; Pitsavos, C.; Panagiotakos, D.B.; Skoumas, J.; Zampelas, A.; Chrysohoou, C.; Stefanadis, C. Mediterranean diet and insulin sensitivity, lipid profile and blood pressure levels, in overweight and obese people; the Attica study. Lipids Health Dis. 2007, 6, 22. [CrossRef] [PubMed]

(C) 2017 by the authors. Licensee MDPI, Basel, Switzerland. This article is an open access article distributed under the terms and conditions of the Creative Commons Attribution (CC BY) license (http:/ / creativecommons.org/licenses/by/4.0/). 